Iberian Journal of the History of Economic Thought

ISSN-e 2386-5768

\title{
Aportes a las traducciones de la obra de Adam Smith
}

Leonidas Montes ${ }^{1}$

CARRIÓN, GONZALO (edición a cargo de), 2017, Escritos Preliminares de la Riqueza de las Naciones y Consideraciones sobre la Primera Formación de las Lenguas de Adam Smith Clásicos del pensamiento, Biblioteca Nueva, 2017, 176 pp. ISBN-10. 8416938393

Con su traducción e introducción a los "Escritos Preliminares de la Riqueza de las Naciones y Consideraciones sobre la Primera Formación de las Lenguas", Gonzalo Carrión ha realizado un aporte importante. Tal como se afirma al inicio de este libro, Adam Smith es un pensador cuyo "reconocimiento" excede con creces al "conocimiento" de su obra. Y esta distancia es aún más aguda en nuestro mundo hispanoamericano. La primera traducción de Una Investigación acerca de la Naturaleza y las Causas de la Riqueza de las Naciones (RN, 1776) de Alonso Ortiz se realizó recién el año 1794 y la primera traducción de La Teoría de los Sentimientos Morales (TSM, 1759) tuvo que esperar más de doscientos años, hasta que finalmente tuvimos disponible la excelente traducción de Carlos Rodríguez Braun en $1997^{2}$.

También es cierto que la suerte de TSM fue diferente a la de RN. En efecto, el impacto de esta última obra eclipsó el éxito inicial de TSM. Si bien TSM fue el libro que le trajo prestigio intelectual y fama a Adam Smith en vida, fue la influencia histórica de RN - un libro muchas veces citado y mencionado, pero pocas veces comprendido a cabalidad - lo que catapultó a Smith como el padre de la economía y dejó a TSM en el olvido. En 1926 James Bonar perceptivamente sostuvo que "la fama de RN permitió mantener viva la memoria de TSM", una memoria que fue muy poco leída. No es casual que durante el siglo XIX y la primera mitad del siglo XX sólo cuatro ediciones de TSM fueran publicadas en inglés.

Pero la razón principal de este olvido es simple. El predominio intelectual que ejercieron el utilitarismo de Bentham y la deontología kantiana opacaron esa teoría ética smithiana fundada no en la razón, sino en una combinación de sentimientos y deliberación racional. La discusión moral de durante el siglo XIX y gran parte del siglo XX estuvo marcada por la autoridad del concepto de utilidad o del deber moral representado por el imperativo categórico. La hegemonía intelectual de ambas corrientes filosóficas encubrió esa riqueza que escondía TSM. Y si a todo esto sumamos las interminables discusiones sobre el famoso Das Adam Smith Problem que sostenía que ambas obras serían incompatibles, la historia convirtió a TSM en una gema filosófica perdida. Peor aún, los economistas prácticamente ignoraron TSM por considerarla una obra de corte psicológico, muy alejada del énfasis matemático que guiaba a la economía neoclásica. ${ }^{3}$ Es más, Friedrich Hayek, quien fuera junto a Keynes el más ilustrado de los economistas del siglo XX, si bien toma y discute algunos pasajes de TSM, no comprendió la importancia de la simpatía y del proceso simpatético (Montes, 2011). TSM era considerada una obra menor, o una simple e incómoda memoria mantenida por la influencia de RN.

Sin embargo en 1976, conmemorando el bicentenario de RN, se inició la publicación del Glasgow Edition of Smith's Works and Correspondece que partió con la publicación de RN y

Cátedra Adam Smith, Escuela de Gobierno

Universidad Adolfo Ibáñez, Chile

Acerca de la recepción de Adam Smith en español, ver Tribe 2002, pp. 184-97 y Trincado 2015.

Por ejemplo, en 1976 se reunieron una serie de destacados economistas (entre ellos Spengler, Buchanan, Baumal y Harry Johnson) para celebrar el bicentenario de RN, pero en la colección de sus ensayos conmemorativos ni siquiera aparece mencionada TSM (ver Glahe 1978). 
TSM. Esta iniciativa de Oxford University Press nos acercó a las obras completas de Adam Smith. La posterior publicación de estas obras por Liberty Fund, que se inició en 1981 con RN y continuó con TSM en 1982, hizo muchísimo más accesible el legado de Adam Smith para miles de académicos y estudiantes. Estas publicaciones han traído, durante los últimos treinta años, un rápido y sostenido auge en la revaluación de TSM y la obra completa de Adam Smith. Economistas como Vernon Smith y Amartya Sen han reiterado una y otra vez la importancia de TSM. Filósofos como Ernst Tugendhat y Martha Nussbaum han puesto de relieve su trascendencia. Desde múltiples y diversas disciplinas del saber, todos los escritos de Adam Smith han sido analizados y auscultados con un inusitado interés. De hecho podría sostenerse que si hasta 1976 la investigación de punta en los estudios smithianos prácticamente se restringía y centraba en RN, hoy la situación es muy diferente. Es más, podemos afirmar que si RN opacó a TSM durante más de doscientos años, el fenómeno se ha invertido. TSM junto a sus "Ensayos Filosóficos", a sus "Lecciones de Retórica" (aún no traducidas al español) y a sus "Lecciones sobre Jurisprudencia" son los textos que hoy llaman la atención del mundo intelectual. Y en este abanico pluridisciplinario, sus "Consideraciones sobre la Primera Formación de las Lenguas" (CPFL) ocupa un lugar muy especial.

Como nos recuerda el autor, este importante ensayo fue publicado originalmente en mayo de 1761 en Philological Miscellany. Posteriormente, en 1767, fue incluido, a petición del mismo Adam Smith, en la tercera edición de TSM (ver Corr. 100, p. 122 donde Smith le pide a su editor William Strahan incluirlo). El ensayo siguió publicándose en las sucesivas ediciones de TSM hasta la sexta y definitiva edición de 1790, publicada pocas semanas antes de su muerte. Gonzalo Carrión acertadamente sugiere que CPFL no sólo es su texto más extenso después de TSM y RN, sino también el que gozaba de mayor aprecio por parte de su autor (pp. 18-19). Por tanto es tan pertinente como provocativa la pregunta que nos sugiere: ¿por qué este ensayo no siguió publicándose, como fue el deseo de Adam Smith, como parte de TSM?

Si bien su fascinante ensayo titulado "Historia de la Astronomía" — el que Schumpeter definió como "la perla de su colección" (Schumpeter, 1954, p. 182) - fue rescatada del fuego y publicado póstumamente como parte de sus "Ensayos Filosóficos" (1795), Smith sólo mantuvo CPFL en una posición destacada. Y esa posición sin lugar a dudas merece mayor atención. En el capítulo 2 del libro I de RN, la parte más fundamental de su magnum opus, Smith investiga las causas de nuestra propensión al intercambio y escribe "No es nuestro tema inquirir sobre si esta propensión es uno de los principios originales de la naturaleza humana, de los que no se pueden dar más detalles, o si, como parece más probable, es la consecuencia necesaria de las facultades de la razón y del lenguaje" (RN, p. 44). El lenguaje, la retórica y en mayor medida la persuasión, son fundacionales no sólo para la economía política de Adam Smith, sino también para su pensamiento político y moral.

La diestra y congruente traducción de CPFL, así como del Borrador y los dos Fragmentos de la división del trabajo, viene acompañada de una muy buena introducción (pp. 9-70), de útiles referencias (pp. 73-83) y de una didáctica cronología (pp. 85-96). CPFL no es un texto fácil de traducir, pero el resultado hace honor a la advertencia del autor cuando éste afirma que "las decisiones de traducción se realizaron tratando de respetar el enfoque histórico-conjetural propio del ensayo smithiano" (p. 97). Esta sana inspiración se cumple con creces y finalmente tenemos este ensayo fundamental en español lo que nos permitirá adentrarnos en la importancia del lenguaje para Adam Smith y las conexiones que emergen con su teoría social.

CPFL es un ensayo necesario para comprender el legado intelectual de Adam Smith, ese filósofo moral "cuyo oficio es no hacer nada pero observarlo todo" (RN, p. 40). Su publicación contribuye al renovado y creciente interés por la amplia y original mirada de este gran intelectual de la Ilustración Escocesa en el mundo hispanoamericano. En fin, este libro es un aporte importante para académicos y estudiantes. Pero también es una muestra palpable del renacimiento de nuestro reciente interés como hispanoparlantes en la "reconocida" pero no necesariamente "conocida" obra de esta gran figura intelectual de la Ilustración Escocesa. 


\section{Referencias}

Glahe, F. R. (1978) Adam Smith and the Wealth of Nations. Bicentennial Essays 1776-1976. Boulder: University of Colorado Press.

Montes, L. (2011) 'Is Hayek rowing Adam Smith's Boat?', in Hayek, Mill, and the Liberal Tradition, edited by Andrew Farrant, London: Routledge.

Schumpeter, J. A. (1954) History of Economic Analysis, Routledge: London.

Smith, A. $(1759,1997)$ La Teoría de los Sentimientos Morales traducida por Carlos Rodríguez Braun. Madrid: Alianza Editorial.

Smith, A. (1776, 1994) Una Investigación acerca de la Naturaleza y las Causas de la Riqueza de las Naciones, traducida por Carlos Rodríguez Braun. Madrid: Alianza Editorial.

Tribe, K. (2002) 'A Critical Biography of Adam Smith', London: Pickering \& Chatto.

Trincado, L. (2011) 'The Translation into Spanish of the Theory of Moral Sentiments by Adam Smith', Adam Smith Review, vol. 8, pp. 38-52. 